M.A. Polyakov, T.Y. Larionova

\title{
EFFICIENCY EVALUATION TECHNIQUE OF THE SEMICONDUCTOR DC-DC CONVERTER APPLICATION IN THE POWER-SUPPLY SYSTEM
}

Purpose. To specify efficiency evaluation of the DC-DC power semiconductor converter application in the power-supply system. Methodology. We have chosen application version of converter and then used the statistical modeling of DC-DC converter for its efficiency evaluation at varied input voltage according to proposed technique. We have compared the simulated result with the data presented in reference literature. Results. We have proposed the efficiency evaluation technique of converter application. Proposed technique includes detection of external factors influenced on the converter efficiency; development of efficiency evaluation models; selecting application version of converter; determination of the correlation coefficients between the values of external factors; definition of the converter efficiency; obtaining of the converter efficiency distribution. Originality. For the first time, we have developed the evaluation technique of converter efficiency corrected for application version of converter. Practical value. Presented in the study results could be useful for specialists in semiconductor equipment, electrical facilities and systems. References 10, figures 8.

Key words: semiconductor converter, efficiency of converter application, statistical modeling, evaluation of the effectiveness, converter efficiency.

Разработана методика оценки эффективности использования полупроводникового преобразователя в системе электроснабжения. Методика включает выявление множества внешних факторов, влияющих на эффективность использование преобразователя; разработку модели оценки эффективности как функции внешних факторов; выбор варианта использования преобразователя; установление коэффициентов корреляции между значениями внешних факторов; определение значений КПД преобразователя; нахождение распределения КПД преобразователя. Применение предложенной методики проиллюстрировано на примере синхронного промежуточного вольтодобавочного преобразователя постоянного напряжения. Для этой цели выполнено статистическое моделирование преобразователя этого типа при стохастичном изменении входного напряжения. Библ. 10 , рис. 8.

Ключевые слова: полупроводниковый преобразователь, эффективность использования преобразователя, статистическое моделирование, оценка эффективности, КПД преобразователя.

Introduction. To meet the power requirements of different types and parameters, and to effectively manage its various distribution converting devices are needed. An important requirement which is presented to the converters is to provide high performance.

Semiconductor converters have a high efficiency, so are widely used in industrial equipment and electric transport [1].

To quantify the efficiency we use the ratio of output power (or energy) to the power consumed by the converter from the mains, at a certain input voltage and load, often nominal. For converters the value of efficiency contained in the documents and is one of the important indicators. Reduced efficiency in converters due to losses in the converter electronic components - power semiconductor devices (PSD), transformers, inductance, capacitance. Basic types of losses in converters are switching losses arising at the switching of power switches, conduction losses and [2]. Known studies [3-5] are aimed at finding the maximum efficiency of the converter which is achieved by selecting the topology optimization of the parameters of passive components, the use of PSD with a low resistance in the conducting state and switching losses, choice of algorithm switching and PSD switching frequency. The quantity also depends on the efficiency of external factors such as input voltage, load resistance, and others. There are a number of applications of semiconductor converters which are characterized by a change in a wide range of input voltage and load current. It is for wind energy converters, power supply from the battery, electric motor and other. Researchers [6] revealed dependence $E=f\left(V_{i n}, I_{o}\right)$ which are the extremum in the middle ranges of values $V_{i n}$ and $I_{o}$. For example, the input voltage of the converter power supply system of own needs (SSON) of electric rolling stock (ERS) varies widely (on the susceptor of the electric rolling stock with a nominal voltage of $3000 \mathrm{~V}$ - from 2200 to $3850 \mathrm{~V}$ [7]). In this case, most of the time converter of the SSON works at non-optimal conditions, its efficiency is reduced [8].

Problem definition. In itself, the value of the efficiency does not provide complete information about the amount of energy loss in the converter in particular its application in the power supply system, as the use mode converter may differ from that in which the efficiency 
was measured. In real terms the converter operates in a range of efficiency. Therefore, to the average evaluating the effectiveness of the use of the converter in the power supply system needs to take into account the nature of the change in time of the input voltage and load. Depending on the application, the converter, these changes can be both deterministic and stochastic.

The goal of the work is to update evaluation the effectiveness of the use of the DC voltage inverter in the power supply system.

For the efficiency density distribution and integral distribution function of the efficiency the applied method of statistical Monte-Carlo simulation is used.

\section{Results of investigations.}

The proposed technique includes the following stages:

1. Identification of a number of external factors $A_{\text {ext }}$ on which the efficiency of the converter depends. As a rule, they are voltage $V_{i n}$ and current $I_{o}$.

2. Development of a model for converter efficiency evaluation as a function of external factors Efficiency = $f\left(A_{\text {ext }}\right)$. As is known, the converter efficiency is determined in the losses of its circuit elements. These losses depend on the ratings and the quality of its circuit elements, and the switching converter topologies key algorithms. At the stage of evaluation of the efficiency of the model are identified depending on the components of loss on external factors values.

3. To select the option of using the converter, which is described by some time interval $\left[t_{1}, t_{2}\right]$, duration $\Delta t$, in time changes the characteristics of the external factor values $A_{\text {ext }}=f(t), t \in\left[t_{1}, t_{2}\right]$ including a range of possible values $\left[A_{\text {ext_min }}, A_{\text {ext_max }}\right]$ and the duration of action to the converter of external factor with a value $A_{\text {ext }}$. At the stochastic nature of the change in time value of external factors $A_{\text {ext }(i)}$ to determine the probability density function of values $A_{\text {ext }(i)}$ on the converter model input.

4. To determine the correlation coefficients between the values of external factors on the inputs of the converter model. These factors are taken into account when setting the values of the dependent from each other external factors. For example, intelligent power supply control system can limit the load at lower voltage $V_{\text {in }}$ to a critical value.

5. To calculate the converter efficiency by modeling his work with the given values of external factors for each subinterval $\Delta t_{i}$ owned interval $\Delta t$. For stochastically changing external factors to conduct a series of experiments with the converter model and the values of the input factors, which are randomly selected, taking into account the probability of occurrence of a given value.

6 . The resulting simulation efficiencies to divide into ranges of values and to determine the relative frequency of efficiency values belonging to each interval. On the basis of these frequencies to determine the density distribution and the cumulative distribution function of the converter efficiency for the selected option of using it.

We illustrate the proposed methodology on the example of evaluating the effectiveness of the use of a synchronous buck-boost DC converter at random variation of the input voltage. Functional diagram of the considered converter is shown in Fig. 1 [9].

To evaluate the effectiveness of the converter we perform actions according to the proposed method.

1. As input factor we selected $V_{\text {in }}$ which, as noted above, significantly influences the efficiency of the converter.

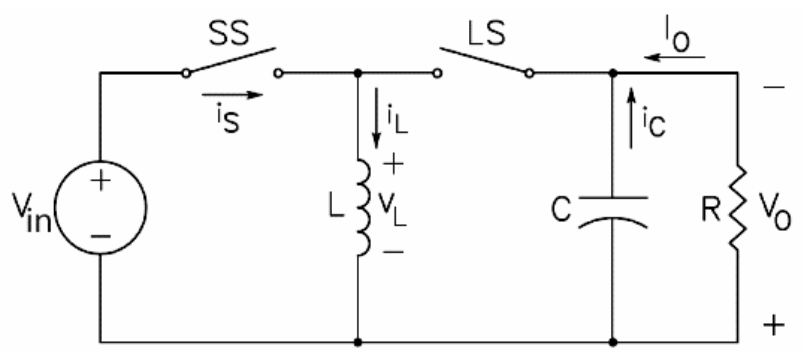

Fig. 1. Functional diagram of a synchronous buck-boost DC converter

2. To obtain the dependence of the efficiency of the converter voltage varying randomly we simulated a synchronous buck-boost DC converter. As the basis of the model a Simulink model of a synchronous DC buck-boost converter with a subsystem that performs the output power, the loss of power and efficiency of the converter calculation is taken [9].

Fig. 2 shows a model of a synchronous buck-boost DC converter and Fig. 3 demonstrates subsystems that perform calculation of output power, power losses and converter efficiency. The model takes into account the main factors affecting the efficiency of the converter: Key resistance in the open state; direct drain-source voltage; duty cycle; operating frequency; fall time and rise time when the key switch; static and dynamic losses in the inductor and the capacitor equivalent series resistance.

The presented in Fig. 3 model for calculation of efficiency determines the power losses in the converter as the sum of the power loss in the switch to the keys (SS Switch Loss and LS Switch Loss), the power loss in the keys in the conductive state (SS Conduction Loss and LS Conduction Loss), losses in «internal» key diode (LS Body Diode Loss), the losses due to «dead time" (DeadTime Loss). 


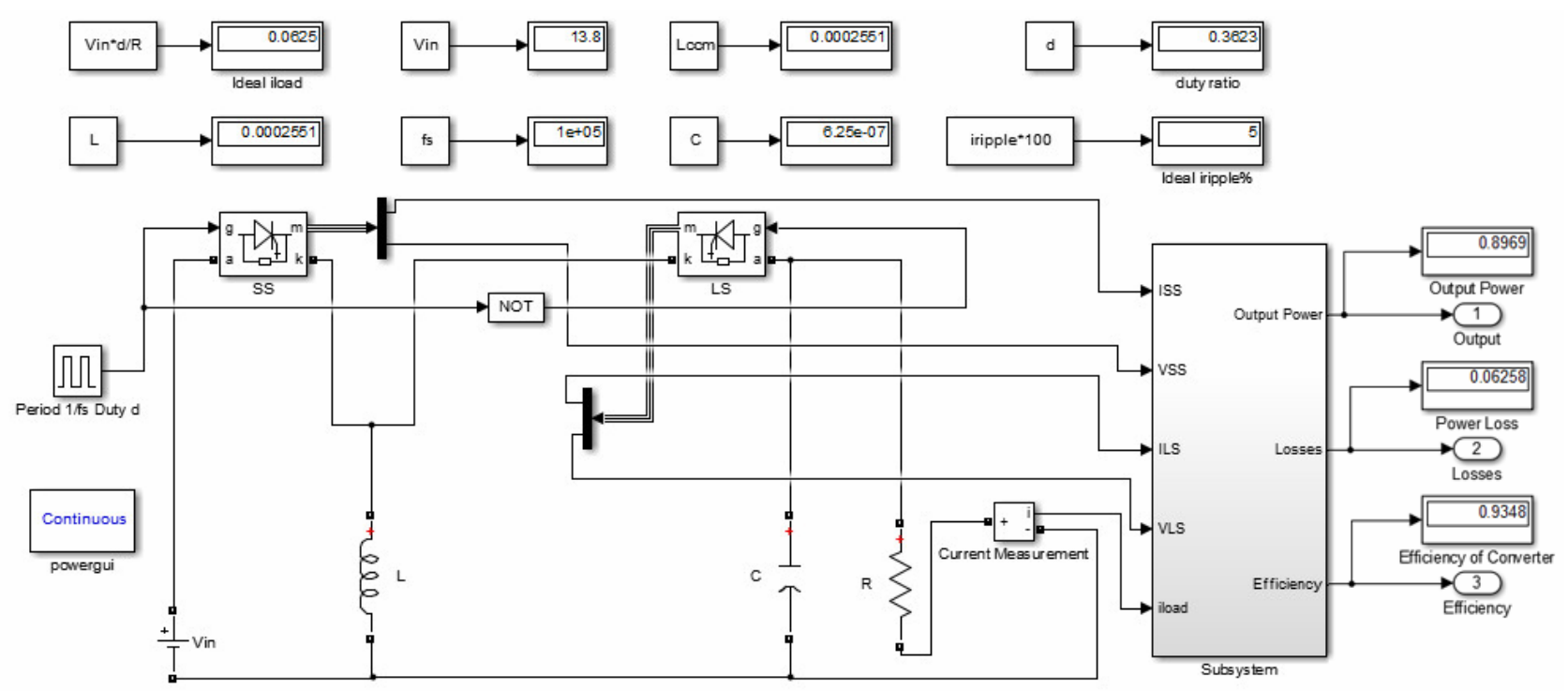

Fig. 2. A model of the synchronous buck-boost DC converter

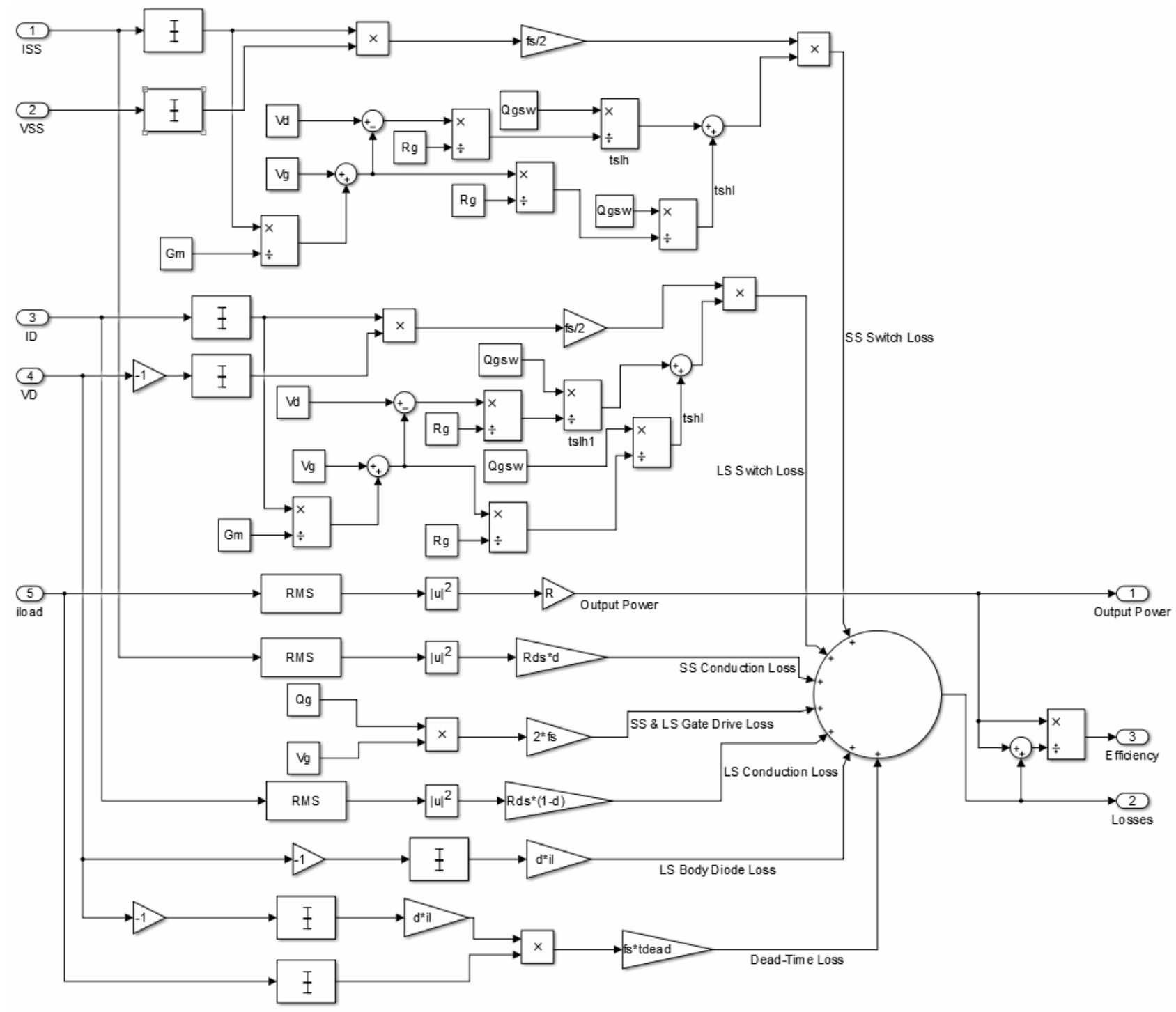

Fig. 3. A model of the subsystem calculating output power, power losses and efficiency 
Parameters values of model's elements not specified in [9] are presented in the $m$-file listing (Fig. 4).

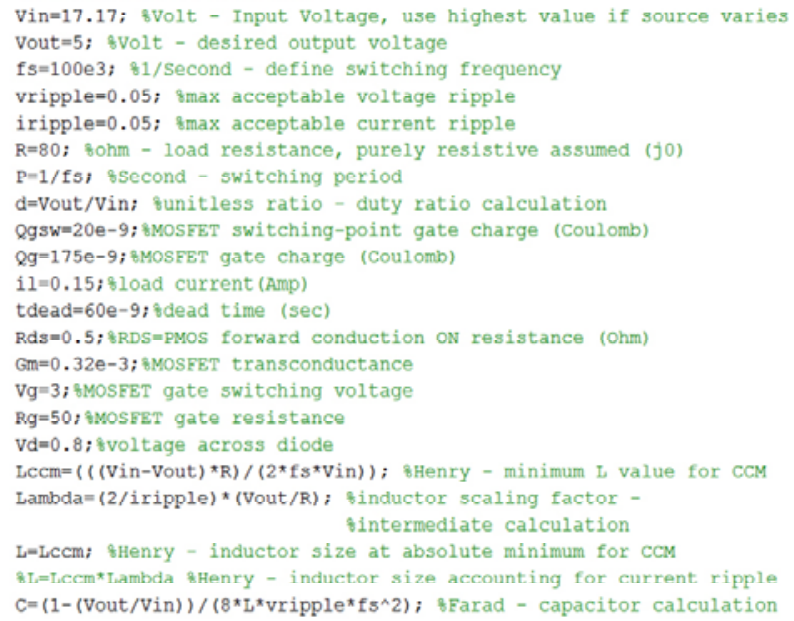

Fig. 4. Listing of the $m$-file setting parameters of the converter's circuit elements

3. We simulate the conditions specific to the converter SSON ERS. The voltage at the input of the converter $\left(V_{\text {in }}\right)$ depends on the voltage of the traction substation, the ERS position relative to the points of the supply voltage to the contact wire, the presence of other loads at the site of the power station, weather conditions and other factors, wearing casual character. In accordance with the provisions of the central limit A.M. Lyapunov theorem if the random variable $x$ is the sum of a very large number of mutually independent random variables, each of which impact on the entire amount is negligible, then $x$ is distributed according to a law close to normal [10]. Therefore, we believe that the input voltage $V_{\text {in }}$ converter has a normal distribution.

The density of the random variable $V_{\text {in }}$ is given by [7]:

$$
f\left(V_{i n} ; \mu, \sigma\right)=\frac{1}{\sigma \sqrt{2 \pi}} e^{-\frac{\left(V_{i n}-\mu\right)^{2}}{2 \sigma^{2}}},
$$

where $\mu$ is the average value (nominal input voltage of the converter); $\sigma$ is the standard deviation.

For a DC converter SSON ERS $[7,10] \mu=3000 \mathrm{~V}$ and $\sigma=2.1$. Modeling the circuit (Fig. 2) we assume $\mu=$ $13.8 \mathrm{~V}$ and $\sigma=2.1$.

Random values of $\mu$ are generated by functions NORM.INV and RAND of the Microsoft Excel Microsoft Office 2010.

Density plot of a probability distribution of the input voltage is shown in Fig. 5. The generated sample consists of 100 values. With this number of values of the maximum relative deviation of the generated density distribution of the density distribution determined by the formula (1) does not exceed $12 \%$ (Fig. 6), which is acceptable in engineering calculations.

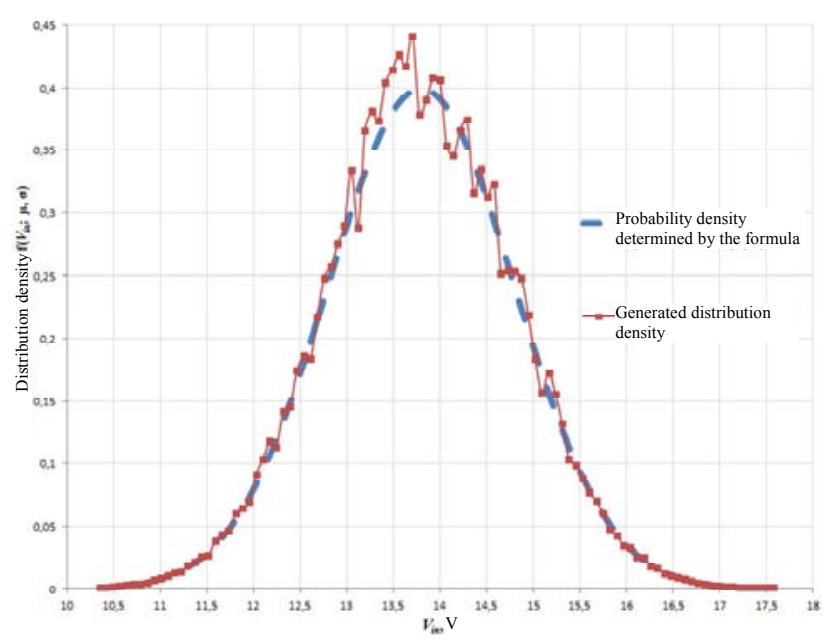

Fig. 5. Probability density generated and determined by formula (1) distribution density of the input voltage value $V_{\text {in }}$

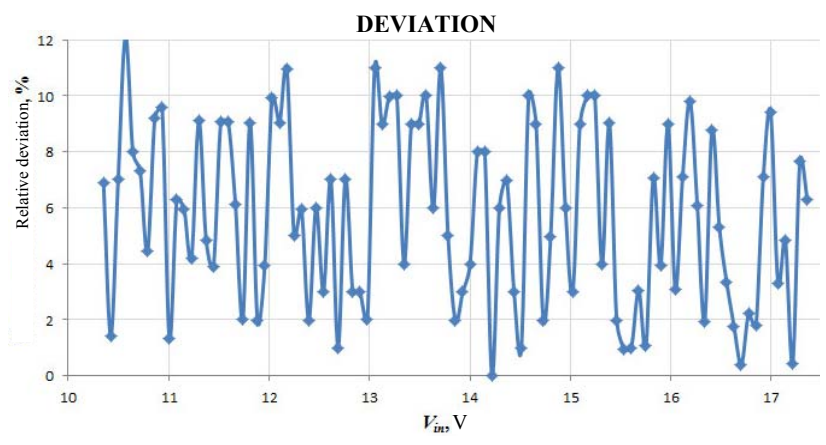

Fig. 6. Relative deviation of the generated distribution

4. As seen in the example of the effect of only one value (input voltage) of the converter efficiency, the correlations between the values of influencing factors are absent.

5. For generated random values $V_{\text {in }}$ we simulated currents in the branches and the voltages in the circuit nodes, as well as the modeling of output power losses and converter efficiency. Simulation results with comparable input data agree to within $1 \%$ of the data obtained in [10].

6. As a result of a series of experiments we obtained 100 values of the converter efficiency which are in the range of 0.9187 to 0.9584 . Further, this range is divided into intervals (in this example - 0.005) and identified the relative and absolute frequency of the efficiency values within each interval. Based on these data, the density distribution plotted converter efficiency (Fig. 7) and the cumulative distribution function converter efficiency (Fig. 8).

The following distribution corresponds to Fig. 6: 


$$
f(E ; \mu, \sigma)=\frac{1}{\sigma \sqrt{2 \pi}} e^{-\frac{(E-\mu)^{2}}{2 \sigma^{2}}},
$$

where $E$ is the converter efficiency; $\mu$ is the average value; $\sigma$ is the standard deviation.

In the correspondence with Fig. 7, $\mu=0.935$ and $\sigma=0.016$.

In accordance with Fig. 8, the probability that the data in the efficiency of the converter at given conditions of use will be not less than 0.935 , it is 0.65 . Thus, account of risks of reducing the efficiency based on the proposed integrated assessment helps to clarify evaluate the effectiveness of the use of the converter in a particular application.

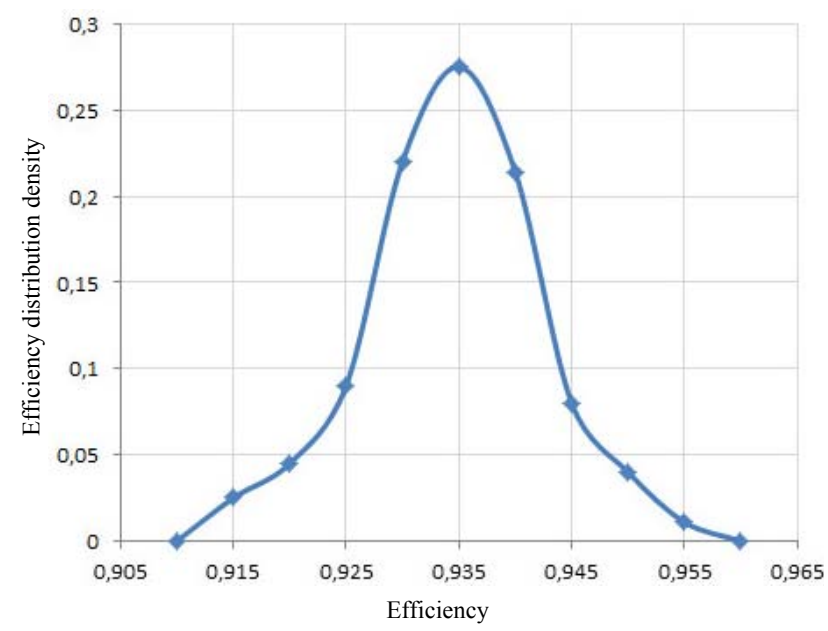

Fig. 7. Inverter efficiency distribution density built by results of stochastic modeling

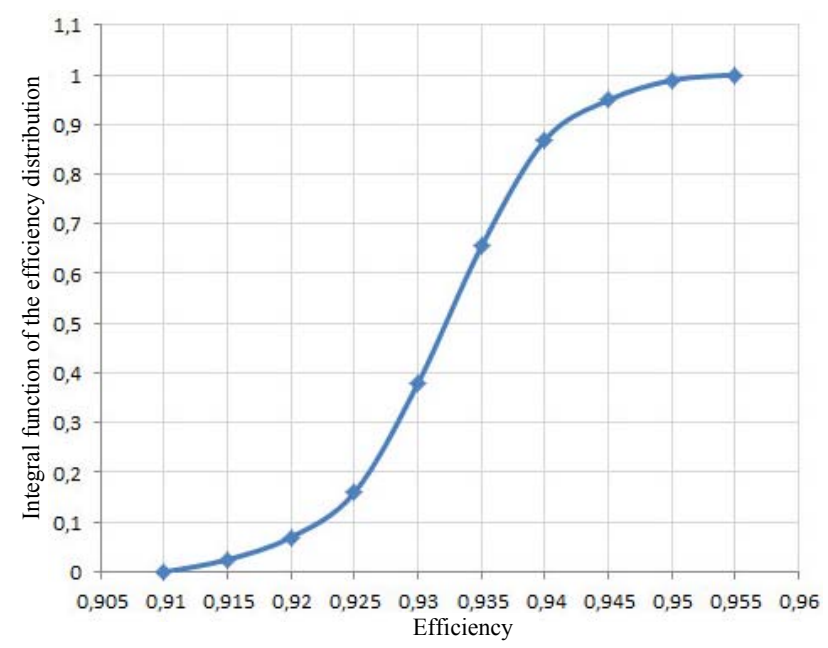

Fig. 8. Integral function of the converter efficiency distribution

\section{Conclusions.}

1. A technique for evaluating the effectiveness of using of a semiconductor DC converter in the power supply system is proposed.

2. It is shown that the calculated by the proposed method the efficiency of the converter utilization is below the average efficiency values defined by the baseline method.

3. It is intended to use obtained results during converter design at the company «NII Preobrazovatel» (Zaporozhye, Ukraine).

\section{REFERENCES}

1. Tittse U., Shenk K. Poluprovodnikovaja shemotehnika [Semiconductor engineering]. Moscow, Mir Publ., 1983. 512 p. (Rus).

2. Lukutin B.V., Obuhov S.G. Silovye preobrazovateli $v$ elektrosnabzhenii [Power converters in electricity supply]. Tomsk, TPU Publ., 2007. 144 p. (Rus).

3. Gildersleeve M., Forghani-zadeh H.P., Rincon-Mora G.A. A Comprehensive Power Analysis and a Highly Efficient, ModeHopping DC-DC Converter. Proceedings. IEEE Asia-Pacific Conference on ASIC, September 2002, pp. 153-156. doi: 10.1109/apasic.2002.1031555.

4. Arvind Raj. Application Report. Calculating Efficiency. PMP-DCDC Controllers: SLVA390 - February 2010. Available at: http://www.ti.com/lit/an/slva390/slva390.pdf (accessed September 28, 2015).

5. Chen M., Afridi K.K., Chakraborty S., Perreault D.J. A high-power-density wide-input-voltage-range isolated $\mathrm{dc}-\mathrm{dc}$ converter having a MultiTrack architecture. 2015 IEEE Energy Conversion Congress and Exposition (ECCE), Sep. 2015. doi: 10.1109/ecce.2015.7309945.

6. Nowakowski R., Tang Ning. Efficiency of synchronous versus nonsynchronous buck converters. Texas Instruments Analog Applications Journal, 2009, no.4Q, pp. 15-18.

7. GOST 6962-75. Transport elektrificirovannyj s pitaniem ot kontaktnoj seti. Rjad naprjazhenij [State Standart 6962-75. Electrified transport with overhead system power supply. Voltage row]. Moscow, Izdatelstvo standartov Publ., 1975. 8 p. (Rus).

8. Larionova T.Y. Comparison of the auxiliary power supply systems of the electric railway rolling stock DC $3000 \mathrm{~V}$ according to the energy efficiency Transactions of Kremenchuk Mykhailo Ostrohradskyi National University, 2015, no.3(92), pp. 34-39. (Rus).

9. Katsikis V. MATLAB - A Fundamental Tool for Scientific Computing and Engineering Applications - Volume 1. InTech Publisher, 2012. 534 p. doi: 10.5772/2557.

10. Sigorskij V.P. Matematicheskij apparat inzhenera. Izd. 2-e. stereotip. [Engineer's mathematical apparatus. 2nd ed. stereotype]. Kyiv, Tekhnika Publ., 1977. 786 p. (Rus). 
M.A. Polyakov ${ }^{1}$, Candidate of Technical Science, Associate

Professor,

T.Y. Larionova ${ }^{1}$, Postgraduate Student,

${ }^{1}$ Zaporozhye National Technical University,

64, Zhukovsky Str., Zaporozhye, 69063, Ukraine.

тел/phone +38061 7698395,

e-mail: polyakov@zntu.edu.ua, electro-eng@yandex.ru

How to cite this article:

Polyakov M.A., Larionova T.Y. Efficiency evaluation technique of the semiconductor DC-DC converter application in the power-supply system. Electrical engineering \& electromechanics, 2016, no.5, pp. 23-28. doi: 10.20998/2074272X.2016.5.03. 